Original Research Article

\title{
The assessment of knowledge, attitude and practice of antibiotic stewardship among healthcare providers in a tertiary care hospital
}

\author{
Akhilesh Kumar, Monica Aggarwal*, Varsha Rathor
}

Department of Pharmacology, Employees State Insurance Corporation Medical College and Hospital, Faridabad, Haryana, India

Received: 15 May 2019 Accepted: 12 June 2019

\section{*Correspondence to: \\ Dr. Monica Aggarwal, Email:monicag@ rediffmail.com}

Copyright: (C) the author(s), publisher and licensee Medip Academy. This is an openaccess article distributed under the terms of the Creative Commons Attribution NonCommercial License, which permits unrestricted noncommercial use, distribution, and reproduction in any medium, provided the original work is properly cited.

\begin{abstract}
Background: Antibiotics are the most commonly used drugs often associated with inappropriate use leading to resistance. While knowledge enlightens and provides an insight into the problems faced, behavioral change solely depends on the beliefs and attitude. Aim of this study to evaluate the knowledge and beliefs about antimicrobial prescribing among prescribers in a teaching tertiary care hospital

Methods: The present study was conducted in the Department of Pharmacology, ESIC Medical College and Hospital, Faridabad. after Ethical clearance from the Institutional Ethics Committee. Design of this study was a prospective, crosssectional study carried out in the form of a survey in which a pretested, semistructured, validated questionnaire of 30 questions was provided to Junior residents, Senior residents and Faculty of different specialties and response was recorded. Questionnaire comprises of 10 questions each in knowledge, attitude and practice section.

Results: Out of 132 prescribers $86.5 \%$ believed that irrational practice will cause global resistant development. majority $(92.3 \%)$ were expressing the need that sample culture should be sent before starting antibiotics but only $69.2 \%$ were of the opinion that culture and sensitivity should be done in all infections and $92.3 \%$ were expressing the view that hospital antibiotics policy is useful in reducing AMR.

Conclusions: The present survey on antibiotic usage gives useful information about the knowledge, attitudes and practices of prescribers and help plan suitable educational interventions that aim at improving the antimicrobial prescribing and minimizing the development of resistance.
\end{abstract}

Keywords: Antimicrobial resistance, Attitude, Knowledge, Practices

\section{INTRODUCTION}

Antimicrobial agents (AMAs) are among the most commonly prescribed drug classes in the developing countries. The irrational and overuse of antimicrobials, results not only in the emergence of resistant bacteria but also results in adverse drug reactions. ${ }^{1}$

Development of antimicrobial resistance is accelerated by excessive antimicrobial prescription. More than $50 \%$ of AMAs worldwide are purchased without prescription. ${ }^{2}$ The situation is more worse in developing countries because of self-medication and over the counter availability of AMAs. ${ }^{1,2}$ Additionally, this practice has also increased the economic burden on national health system. ${ }^{1}$ This has been partly attributed to the lack of physicians' concerns about long term resistance along with the sale of AMAs without prescription in some countries. ${ }^{3}$ Despite severe consequences and global spread of antimicrobial resistance, the effective dissemination of information to the prescribers regarding AMAs misuse remains challenging. ${ }^{4}$ There is growing evidence that hospital based programmes, known as "Antibiotic Stewardship Programmes" which are dedicated to optimize antibiotic use in hospital, can guide clinicians on antibiotic use, improve the frequency of correct prescribing, improve quality of care to patients, reduce 
development of drug resistance/ treatment failure, prevention of adverse effects of drugs, curb the expenses on unnecessary drug usage. According to the World Health Organization, education of healthcare workers and medical students on rational antimicrobial prescribing or "antimicrobial stewardship" is an integral part of all antimicrobial resistance containment activities. 5,6 The present study is designed to assess the knowledge and beliefs about antimicrobial use in 132 prescribers of ESIC Medical College and Hospital.

\section{METHODS}

The present study was conducted in the Department of Pharmacology, ESIC Medical College and Hospital, Faridabad. The Ethical clearance for the study was obtained from the Institutional Ethics. This was a prospective, cross-sectional study which was carried out in the form of a survey in which a pretested, semi-structured, validated questionnaire was administered to the prescribers. Total number 132 participants including JRs, SRs and Faculty of different specialties of ESIC medical College and its associated hospital were included in the study.

Data was analyzed after applying the descriptive statistics. A questionnaire comprising of 30 question with 10 question each in knowledge, attitude and practice section was given to participants and their response was latter analyzed for assessment.

\section{Type and duration of study}

This was a preformed questionnaire-based cross-sectional study and duration of the study was 2 months ( $1^{\text {st }}$ Jan 2019 to $28^{\text {th }} \mathrm{Feb} 2019$ ).

\section{Inclusion criteria}

Junior residents, Senior residents and Faculty of different specialties of ESIC medical College and its associated hospital were included in the study.

\section{Exclusion criteria}

First-, second- and third-year students and interns were excluded from the study.

\section{RESULTS}

\section{Participants' knowledge about antimicrobial resistance (Table 1)}

The 92.3 percent of the participants had knowledge that higher antibiotics should be reserved and used after authentication from senior physician but still $7.7 \%$ were giving opinion of using antibiotics for treatment of cough and cold. $82.7 \%$ were confident of knowledge of antibiotics and their use in common practice and same percentage of participants were also of the opinion that culture and sensitivity should be taken before starting antibiotics as shown in Table 1, About $21.2 \%$ of participants were not aware of antibiotics policy in hospital so there was considerable chance of prescribing resistant antibiotics in the form of empirical therapy. $42.3 \%$ participants were of the view that resistant drug can become sensitive which contradicts to our finding as mentioned above that $82.7 \%$ were confident of knowledge of antibiotics.

\section{Participants' attitude towards antimicrobial resistance (Table 2)}

When assessing the attitude of participants towards antimicrobial resistant (AMR) $86.5 \%$ believed that irrational practice will cause global resistant development. $90.4 \%$ were of the opinion that pharmacist should not be allowed to dispense antibiotics as an OTC medicine as major cause of AMR is because of irrational use of antibiotics. Almost all $(100 \%)$ were of the opinion that patient should be educated regarding rational use of antibiotics and thus preventing the injudicious use. In our findings majority (92.3\%) were expressing the need that sample culture should be sent before starting antibiotics but only $69.2 \%$ were of the opinion that culture and sensitivity should be done in all infections and $92.3 \%$ were expressing the view that hospital antibiotics policy is useful in reducing AMR.

It feels that practitioner know culture sensitivity is important but are not considering for sensitivity test in all infections as sensitivity reports take time. $86.5 \%$ believed that cost should be considered before starting treatment as this could help decrease health expenditure. knowledge don't seem to change attitude when asked about the importance of combination of antibiotics in preventing AMR as only $65.4 \%$ responded positively but in country like India where there are many infectious disease like tuberculosis whose prevalence can be decreased only when combination medicine are used.

\section{Participants' practice assessment (Table 3)}

Lack of establishment in providing favorable environment to increase outcome has always been a hurdle in achieving any goals as it is evident in our study that $88.5 \%$ of participants don't have antibiotics policy of hospital so they rely on physician acumen and empirical therapy while prescribing antibiotics. So, as a result they follow senior physician advice while prescribing as evident in our study that $71.2 \%$ follow senior's advice. The $55.8 \%$ of participant says they follow de-escalation practice but $90.4 \%$ prefer higher antibiotics in spite of lower antibiotics being sensitive and $5.8 \%$ don't know what de-escalation is, it seems practitioner don't want to take risk of using lower antibiotics due to absence of hospital antibiotics policy and fear of poor outcome of treatment in the absence of sensitivity test done .this is supported by the fact that $73.1 \%$ of participants don't take the help of microbiologist or pharmacologist to choose drugs. Despite 
all of these $88.5 \%$ are confident of choosing appropriate dose and $90.4 \%$ of choosing right antibiotics combinations. In their common practice about $84.6 \%$ practitioner educate patient on use of rational antibiotics.

Table 1: Participants' knowledge about antimicrobial resistance.

\begin{tabular}{|clll|}
\hline & & Yes (\%) & No (\%) \\
\hline 1. & Patients with common cold symptoms need antibiotic treatment & 7.7 & 90.4 \\
\hline 2. & The efficacy is better if the antibiotics are newer and more costly? & 9.6 & 88.5 \\
\hline 4. & It is always better to over-prescribe antibiotics than under-prescribe? & 5.8 & 94.2 \\
\hline 5. & Are you awould be able to buy antibiotics without a prescription? & 3.8 & 96.2 \\
\hline 6. & You feel confident about your knowledge and practice in the area of \\
& antimicrobial prescribing? & 78.8 & 21.2 \\
\hline 7. & Sample for culture and sensitivity should be taken before starting antibiotic & 82.7 & 17.3 \\
\hline 8. & Are you aware of antibiotic escalation and de escalation & 82.7 & 17.3 \\
\hline 9. Resistant drug can become sensitive again & 42.5 & 36.5 \\
\hline 10. Higher antibiotics use should be reserved and could be used only after & 92.3 & 55.8 \\
\hline
\end{tabular}

Table 2: Participants' attitude towards antimicrobial resistance.

\begin{tabular}{|clll|}
\hline 1. & Hospital Antibiotic policy is useful in reducing AMR & Yes (\%) & No (\%) \\
\hline 2. & Combination of antibiotics can prevent development of AMR & 92.3 & 5.8 \\
\hline 3. & $\begin{array}{l}\text { Microbiologist should be consulted when required about Antibiotic } \\
\text { prescription }\end{array}$ & 65.4 & 34.6 \\
\hline 4. & Culture and sensitivity test should be done in all infections & 76.9 & 21.2 \\
\hline 5. & Sample for culture should be sent before starting antibiotics & 69.2 & 30.8 \\
\hline 6. & $\begin{array}{l}\text { De-escalation of drugs from higher to lower class is beneficial in reducing } \\
\text { AMR }\end{array}$ & 92.3 & 7.7 \\
\hline 7. & Irrational practice locally will not matter for global resistance development & 13.5 & 46.2 \\
\hline 8. & $\begin{array}{l}\text { Dispensing of antibiotics over the counter for minor ailments by pharmacists } \\
\text { should be allowed }\end{array}$ & 9.6 & 86.5 \\
\hline 9. & Patients should be educated regarding Rational use of antibiotics & 100 & 90.4 \\
\hline 10. Cost should be considered before starting the Treatment & 86.5 & 0 \\
\hline
\end{tabular}

Table 3: Participants' practice assessment.

\begin{tabular}{|llll|}
\hline 1. & Do you have a copy of Antibiotic policy of your hospital? & Yes (\%) & No (\%) \\
\hline 2. & $\begin{array}{l}\text { Do you practice consulting senior physician before prescribing higher } \\
\text { antibiotics? }\end{array}$ & 71.5 & 28.5 \\
\hline 3. & Do you follow de-escalation practices? & 40.4 & 55.8 \\
\hline 4. & Do you implement antibiotic policy in your practice? & 80.8 & 19.2 \\
\hline 5. & $\begin{array}{l}\text { Do you escalate to higher antibiotic treatment inspite of lower antibiotics } \\
\text { being sensitive? }\end{array}$ & 90.4 & 9.6 \\
\hline 6. & $\begin{array}{l}\text { Do you take help of pharmacologist/clinical microbiologist to choose } \\
\text { drugs? }\end{array}$ & 25.0 & 73.1 \\
\hline 7. & Do you educate the patients on rational antibiotic use? & 84.6 & 15.4 \\
\hline 8. & $\begin{array}{l}\text { Do you send sample for culture \& sensitivity test in every case before } \\
\text { starting antibiotics }\end{array}$ & 34.6 & 65.4 \\
\hline 9. & Are you sure about choosing the appropriate dose of antibiotics? & 88.5 & 11.5 \\
\hline 10. Are you sure about choosing the combination of antibiotics when \\
necessary?
\end{tabular}




\section{DISCUSSION}

The study was conducted to evaluate the knowledge, attitude and practice of resident doctors towards antibiotic resistance and prescription. Most of the participants in our study were of the opinion that Antibiotic resistance has become a serious public health problem. In many similar studies like Yashin et al, Jorak et al, participants expressed the same concerned of indiscriminate use of antibiotics. ${ }^{7,8}$ Common ailments like common cold should be dealt with antibiotics was expressed by only $7.7 \%$ participants. Similar findings were observed in Yashin et al, study were participants believed $89.7 \%$ believed that common cold don't require antibiotics course. ${ }^{7}$ Increased usage of antibiotics, in turn can result in an increase in antibiotic resistance. ${ }^{9}$

Since now a day there is no restriction on Over the Counter (OTC) dispensing of antibiotics without prescriptions so any antibiotics can be purchased OTC without prescriptions. ${ }^{10,11}$ These kinds of practices may cause abuse of antibiotics among the populations leading to development of resistance. In this study total $90.4 \%$ participants agree that there is abuse of antimicrobials which is supported by similar results as obtained by Tarao MS et al. Practitioner should be regularly informed about antibiotics resistance pattern and avoid injudicious use. ${ }^{12}$

Trust is associated with increased satisfaction and adherence to treatment, which is reflected as the restrictive attitude towards self-medication, McKinstry et al. Health care providers can educate the common public during consultations as $84.6 \%$ in our study agreed that they take time to explain in detail how antibiotics are to be used and discourage self-medication and injudicious use. ${ }^{13}$

Limitation of the study:

- Lack of Antibiotics Policy in our Hospital

- Since our Hospital/Medical College is new and Antibiotics is not in place, it would have been better if we could compare present study with KAP of Doctors after training in Antibiotics Stewardship.

Strength of the study

- This is the first of its kind study in our hospital. It will help in formulating the antibiotic policy of our hospital

- Also it will help propagate awareness about antibiotic stewardship among healthcare prescribers. In the long run this will be a step to curb the growing menace of antimicrobial resistance.

\section{CONCLUSION}

This study highlighted the need for educating medical fraternity regarding appropriate antibiotic use and resistance. The study also demonstrated disparities between knowledge and practice; doctors had some knowledge and so accordingly some application in real practice. More emphasis should be on the practice of antibiotic prescription rather than knowledge and attitude. Emphasis should be placed on correct prescribing rules and prevention of inappropriate use thus more on practice than knowledge and attitude. Implementation of an antimicrobial stewardship program for medical students should be ensured in order to standardize the prescribing behaviors of our future doctors.

\section{ACKNOWLEDGEMENTS}

Authors would like to thank the students and doctors who participated in the study for their input, dedication and enthusiasm.

\section{Funding: No funding sources}

Conflict of interest: None declared

Ethical approval: The study was approved by the Institutional Ethics Committee

\section{REFERENCES}

1. Gyssens, IC. Quality measures of antimicrobial drug use. Int J Antimicrob Agents. 2001;17:9-19.

2. Damisie G, Hambisa S, Yimam M. Over the Counter Sale of Antibiotics at Drug Stores Found in MizanAman Town, Southwest Ethiopia: A Cross-Sectional Simulated Client Visit Study. J Pharmaceutics Article. 2019:2019;6.

3. Shehadeh M, Suaifan G, Darwish RM, Wazaify M, Zaru L, Alja'fari S. Knowledge, attitudes and behavior regarding antibiotics use and misuseamong adults in the community of Jordan. A pilot study. Saudi Pharmaceut J. 2012Apr1;20(2):125-33.

4. Charani E, Cooke J, Holmes A. Antibiotic stewardship programmes-what's missing? J Antimicrob Chemother. 2010Sep16;65(11):2275-7.

5. Widayati A, Suryawati S, de Crespigny C, Hiller JE. Knowledge and beliefs about antibiotics among people in Yogyakarta City Indonesia: a cross sectional population-based survey. Antimicrobial Resistance and Infection Control. 2012;1(1):38.

6. Abbo LM, Cosgrove SE, Pottinger PS, Pereyra M, Sinkowitz-Cochran R, Srinivasan A, et al. Medical Students' Perceptions and Knowledge AboutAntimicrobial Stewardship: How Are We Educating Our Future Prescribers? Medical Students and Antimicrobial Stewardship. 2013May 31;57(5):631-8.

7. Yashin AN, Thakuria N, Narzary H, Satnami D, Paul N. A questionnaire based survey on the knowledge, attitude and practices about antimicrobial resistance and usage among the MBBS students and doctors of a tertiary care teaching Hospital in Silchar, Assam, India. Int J Basic Clin Pharmacol. 2018;7:1630-6.

8. Jorak, A. A Cross Sectional Study on Knowledge, Attitude and Practice of Medical Students towards 
Antibiotic Resistance and its Prescription, Iran. Adv Environ Biol. 2014:8(17):675-81.

9. Chatterjee D, Sen, S, Begum SA, Adhikari A, Hazra A, Das AK. A questionnaire based survey to ascertain the views of clinicians regarding rational use of antibiotics inteaching hospitals of Kolkata. Indian $\mathrm{J}$. Pharmacol. 2015Jan;47(1):105-8.

10. Rathnakar UP, Sharma NK, Garg R, Unnikrishnan B, Gopalakrishna HN. A study on the sale of antimicrobial agents without prescriptions in pharmacies in an urban area in South India. J Clin Diagn Res. 2012;6(6):951-4.

11. Saradamma RD, Higginbotham N, Nichter M. Social factors influencing the acquisition of antibiotics without prescription in Kerala State, South India. Soc Sci Med. 2000;50(6):891-903.

12. Tarao MS, Nulla P, Zingpi M, Agatha G. A Study on the Knowledge, Attitude, Perceptions and Practices of
Antibiotic Usage and Resistance among the Medical Students of JNIMS, Imphal, Manipur. J Evi Based Med Healthca. August2015;2(34):5262-8.

13. Rolfe A, Cash-Gibson L, Car J, Sheikh A, McKinstry B. Interventions for improving patients' trust in doctors and groups of doctors. Cochrane Database of Systematic Reviews. Cochrane Database Syst Rev. 2014Mar4;(3):CD004134.

Cite this article as: Kumar A, Aggarwal M, Rathor $\mathrm{V}$. The assessment of knowledge, attitude and practice of antibiotic stewardship among healthcare providers in a tertiary care hospital. Int $\mathrm{J}$ Basic Clin Pharmacol 2019;8:1766-70. 